\title{
Commentary in reply to a publication on Plasmodium falciparum pre-erythrocytic stage vaccine development
}

\author{
François P. Roman ${ }^{*}$, Margherita Coccia and Lode Schuerman
}

\begin{abstract}
We have read the publication of Molina-Franky and colleagues on Plasmodium falciparum pre-erythrocytic stage vaccine development (Malaria Journal, 2020;19:56). The commentary revises some of their statements on the RTS,S/AS01 vaccine that are considered either imprecise or incorrect.
\end{abstract}

Keywords: Malaria vaccine, Clinical studies, RTS,S/AS01

\section{Main text}

While we agree that efforts to find and introduce new candidate pre-erythrocytic malaria vaccines are warranted, we disagree with the statement of Molina-Franky and colleagues [1] that none of these approaches has led to promising results regarding an effective control of the disease. It is indeed our opinion that the results available today for RTS,S/AS01, and based on at least 28 clinical Phase I, II and III studies [2] (and not five studies as suggested in Table 1 of the paper) do indicate the potential of this vaccine to provide substantial public health benefit. This is well supported by the European Medicine Agency (EMA) (as reflected in their positive scientific opinion [3]), the World Health Organization (WHO) (as reflected in the WHO position paper on this vaccine [4]) and the national regulatory authorities in Ghana, Kenya and Malawi [5].

We would also like to address some of the specific points raised by the paper. The authors state that "A tetrapeptide from the CSP NANP tandem repeat region (R) and the $\mathrm{C}$-terminal region containing $\mathrm{T}$ cell $(\mathrm{T})$ epitopes (exclusive for the NF54 strain) are fused to the hepatitis B surface (S) antigen". However, each RTS

${ }^{*}$ Correspondence: francois.p.roman@GSK.COM

GSK, Avenue Fleming 20, 1300 Wavre, Belgium molecule includes 19 copies of the tetrapeptide repeat motif (NANP). In addition, the fact that the C-terminal region of the CSP protein included in the vaccine is derived from the NF54 parasite strain does not mean that it is exclusive for that strain [6-8].

With reference to the WHO position paper on Malaria vaccine [4], the authors state that the EMA issued a "cautious scientific opinion regarding its quality". However, neither the WHO position paper, nor EMA, qualified the positive scientific opinion as cautious, and no specific caution was expressed on the quality of the RTS,S/AS01 vaccine in particular.

The authors also address a series of other concerns relating to the profile of RTS,S/AS01 or to some of its components, such as the genetic variability of the selected CSP region, high parasitaemia levels in "individuals considered protected", presumed pro-apoptotic signals induced by some RTS,S components, or a lack of mechanistic understanding of the AS01 adjuvant system used in the vaccine.

Regarding CSP variability, we know that in the large phase III trial where efficacy was demonstrated against malaria, fewer than $10 \%$ of the parasites matched the CSP protein alleles used in the vaccine [9]. These reassuring data clearly mitigate the concern that CSP variability may neutralize vaccine efficacy.

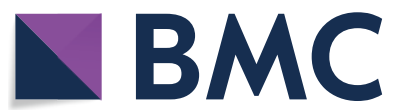

(c) The Author(s) 2020. This article is licensed under a Creative Commons Attribution 4.0 International License, which permits use, sharing, adaptation, distribution and reproduction in any medium or format, as long as you give appropriate credit to the original author(s) and the source, provide a link to the Creative Commons licence, and indicate if changes were made. The images or other third party material in this article are included in the article's Creative Commons licence, unless indicated otherwise in a credit line to the material. If material is not included in the article's Creative Commons licence and your intended use is not permitted by statutory regulation or exceeds the permitted use, you will need to obtain permission directly from the copyright holder. To view a copy of this licence, visit http://creativecommons.org/licenses/by/4.0/. The Creative Commons Public Domain Dedication waiver (http://creativecommons.org/publicdomain/zero/1.0/) applies to the data made available in this article, unless otherwise stated in a credit line to the data. 
High parasitaemia levels (i.e. $>5000$ parasites $/ \mu$ or $0.1 \%$ parasitaemia) are not unexpected after RTS,S vaccination, since the objective of the vaccination is not to prevent infection but to reduce the risk of clinical episodes of malaria. During RTS,S vaccine development the $>5000$ parasites/ $\mu$ l threshold was used to define clinical cases of malaria to evaluate vaccine efficacy, but not as a direct efficacy surrogate of the vaccine [10-14]. A child with a parasitaemia of 5000 parasites/ $\mu$ l or more was not considered to be protected, but on the contrary to experience a malaria episode.

It is unclear why the authors attribute pro-apoptotic signals to RTS,S components, based on the references provided in the manuscript $[15,16]$. From our own review on the two cited papers, such pro-apoptotic signals are described as potential malaria disease-related mechanisms, or as B-cell based mechanisms in the context of influenza vaccination, but not as RTS,S/AS01related mechanisms. Importantly, the actual clinical implications of this statement are unclear.

Finally, albeit the mechanism of action of AS01 is indeed complex, significant published work exists now that clarify many of its aspects $[17,18]$, including the mechanisms of QS21 when formulated in liposomes [19, 20].

\section{Acknowledgements}

Authors would like to thank Fabienne Danhier (Modis c/o GSK) for manuscript coordination.

\section{Authors' contributions}

FPR, MC and LS wrote and approved the manuscript and, as corresponding author, FPR took final responsibility for the content of the submitted manuscript. All authors read and approved the final manuscript.

\section{Funding}

GSK funded the costs associated with the development of the present manuscript.

\section{Availability of data and materials}

The authors declare that all data supporting the findings of this study are available within the article and its additional files.

\section{Ethics approval and consent to participate}

As the present manuscript (Commentary) is not a clinical study, there was no need neither for ethics committee approval nor for informed consent to participate.

\section{Consent for publication}

No details on individuals are reported within the manuscript, therefore consent for publication of images is not applicable.

\section{Competing interests}

François P. Roman, Margherita Coccia and Lode Schuerman are employees of the GSK group of companies hold shares in the GSK group of companies, have full access to the data included in the current work and have final responsibility for the decision to submit for publication.

Received: 25 May 2020 Accepted: 13 July 2020

Published online: 20 July 2020
References

1. Molina-Franky J, Cuy-Chaparro L, Camargo A, Reyes C, Gómez M, Salamanca DR, et al. Plasmodium falciparum pre-erythrocytic stage vaccine development. Malar J. 2020;19:56.

2. Agnandji ST, Fernandes JF, Bache EB, Ramharter M. Clinical development of RTS, S/AS malaria vaccine: a systematic review of clinical Phase I-III trials. Future Microbiol. 2015;10:1553-78.

3. European Medicine Agency Mosquirix H-W-2300. https://www.ema. europa.eu/en/mosquirix-h-w-2300. Accessed 27 Feb 2020.

4. Malaria vaccine: WHO position paper. Wkly Epidemiol Rec. 2016;91:33-52.

5. WHO. Q\&A on the Malaria Vaccine Implementation Pilot (MVIP): https:// www.who.int/malaria/media/malaria-vaccine-implementation-qa/en/. Accessed 27 Feb 2020.

6. Ballou WR. Malaria vaccines in development. Expert Opin Emerg Drugs. 2005;10:489-503.

7. Vekemans J, Leach A, Cohen J. Development of the RTS, S/AS malaria candidate vaccine. Vaccine. 2009;27(Suppl 6):G67.

8. Cohen J, Nussenzweig V, Nussenzweig R, Vekemans J, Leach A. From the circumsporozoite protein to the RTS,S/AS candidate vaccine. Human Vaccin. 2010;6:90-6.

9. Neafsey DE, Juraska M, Bedford T, Benkeser D, Valim C, Griggs A, et al. Genetic diversity and protective efficacy of the RTS, S/AS01 malaria vaccine. N Engl J Med. 2015;373:2025-37.

10. Leach A, Vekemans J, Lievens M, Ofori-Anyinam O, Cahill C, Owusu-Agyei $S$, et al. Design of a phase III multicenter trial to evaluate the efficacy of the RTS, S/AS01 malaria vaccine in children across diverse transmission settings in Africa. Malar J. 2011;10:224.

11. The RTS,S Clinical Trials Partnership. First results of phase 3 trial of RTS,S/ AS01 malaria vaccine in African children. N Engl J Med. 2011;365:1863-75.

12. The RTS,S Clinical Trials Partnership. A phase 3 trial of RTS,S/AS01 malaria vaccine in African infants. N Engl J Med. 2012;367:2284-95.

13. The RTS,S Clinical Trials Partnership. Efficacy and safety of the RTS,S/ AS01 malaria vaccine during 18 months after vaccination: a phase 3 randomized, controlled trial in children and young infants at 11 African sites. PLoS Med. 2014;11:e1001685.

14. The RTS,S Clinical Trials Partnership. Efficacy and safety of RTS,S/AS01 malaria vaccine with or without a booster dose in infants and children in Africa: final results of a phase 3 , individually randomised, controlled trial. Lancet. 2015;386:31-45.

15. Chaudhury S, Ockenhouse CF, Regules JA, Dutta S, Wallqvist A, Jongert E, et al. Malar J. 2016;15:301.

16. Kurup SP, Butler NS, Harty JT. T cell-mediated immunity to malaria. Nat Rev Immunol. 2019;19:457-71.

17. Didierlaurent AM, Collignon C, Bourguignon P, Wouters S, Fierens $K$, Fochesato $\mathrm{M}$, et al. Enhancement of adaptive immunity by the human vaccine adjuvant ASO1 depends on activated dendritic cells. J Immunol. 2014;193:1920-30.

18. Coccia M, Collignon C, Hervé C, Chalon A, Welsby I, Detienne S, et al. Cellular and molecular synergy in ASO1-adjuvanted vaccines results in an early IFNy response promoting vaccine immunogenicity. NPJ Vaccines. 2017;2:25.

19. Detienne S, Welsby I, Collignon C, Wouters S, Coccia M, Delhaye S, et al. Central role of $\mathrm{CD} 169^{+}$lymph node resident macrophages in the adjuvanticity of the QS-21 component of AS01. Sci Rep. 2016;6:39475.

20. Welsby I, Detienne S, N'Kuli F, Thomas S, Wouters S, Bechtold V, et al. Lysosome-dependent activation of human dendritic cells by the vaccine adjuvant QS-21. Front Immunol. 2017;7:663.

\section{Publisher's Note}

Springer Nature remains neutral with regard to jurisdictional claims in published maps and institutional affiliations. 